HYPOTHESIS

\title{
Increased prevalence of imprinting defects in patients with Angelman syndrome born to subfertile couples
}

\author{
M Ludwig, A Katalinic, S Groß, A Sutcliffe, R Varon, B Horsthemke
}

J Med Genet 2005;42:289-291. doi: 10.1136/jmg.2004.026930

Recent case reports have suggested that infertility treatment with intracytoplasmic sperm injection (ICSI) may increase the risk of imprinting defects leading to Angelman syndrome (AS). Although imprinting defects account for only $4 \%$ of patients with AS, we have found four cases among 16 AS patients born to subfertile couples, who conceived with or without infertility treatment $(25 \%$; relative risk (RR) 6.25; 95\% confidence interval (CI) 1.68 to 16.00). The risk in untreated couples with time to pregnancy (TP) exceeding 2 years was identical to that of those treated by ICSI or by hormonal stimulation alone (RR $6.25 ; 95 \% \mathrm{Cl}$ 0.70 to 22.57). It was twice as high in couples who had received treatment and also had TTP $>2$ years (RR 12.5; $95 \% \mathrm{Cl} 1.40$ to 45.13 ). Our findings suggest that imprinting defects and subfertility may have a common cause, and that superovulation rather than ICSI may further increase the risk of conceiving a child with an imprinting defect.

See end of article for authors' affiliations

Correspondence to:

Dr M Ludwig,

Endokrinologikum

Hamburg, Zentrum für

Hormon und

Stoffwechselerkrankungen, Gynäkologische

Endokrinologie und

Reproduktionsmedizin,

Lornsenstrasse 6, 22767

Hamburg, Germany;

michael.ludwig@

endokrinologikum.com

Received

6 September 2004

Revised 25 October 2004

Accepted 29 October 2004 ntracytoplasmic sperm injection (ICSI) was introduced in the early 1990s to treat cases of severe male factor infertility. ${ }^{1}$ From the very beginning there has been concern about increased health risks in children conceived by ICSI. Large follow up studies have shown that the risk of major malformations, low birth weight, and pregnancy complications is increased after in vitro fertilisation, but independent of the use of ICSI. ${ }^{2-5}$

Recent case reports on three children who were conceived by ICSI and have Angelman syndrome (AS) as the result of an imprinting defect on chromosome 15 have suggested that artificial reproduction may increase the risk of imprinting defects. ${ }^{67}$ Similar observations have been made for children with BeckwithWiedeman syndrome. ${ }^{8-10}$

AS is a rare neurogenetic syndrome characterised by microcephalus, jerky movements, absence of speech, abnormal EEG pattern, severe mental retardation, and frequent laughing (incidence, 1 in 15000 newborns). It is caused by the loss of function of the maternal UBE3A allele on chromosome 15. UBE3A is subject to genomic imprinting and, in brain, is expressed on the maternal chromosome only. Approximately $70 \%$ of patients have a deletion on the maternal chromosome, $10 \%$ have a mutation in the UBE3A gene, $4-7 \%$ have two paternal copies of chromosome 15 (uniparental disomy), and 3-4\% have an imprinting defect (ID) that silences the maternal UBE3A allele. In the remaining cases, the patients have some other, hitherto unknown defect. ${ }^{11}$ The relative frequencies of the different genetic defects do not vary between different ethnic groups.

To investigate a possible correlation between infertility treatment and imprinting defects, we performed a cohort study in Germany using data from the German Angelman Syndrome Support Group.

\section{METHODS}

All members of the German Angelman Syndrome Support Group were contacted by a letter and asked to provide, on a voluntary basis, anamnestic data and also information on the method of conception and the time to pregnancy (TTP). The study was approved by the ethics review board of the Ärztekammer Hamburg. Patients gave written informed consent. Parents who stated that TTP exceeded 2 years and/or who had undergone infertility treatment were asked to provide a blood sample ( $10 \mathrm{ml}$ EDTA) or buccal smear from themselves and the child.

The methylation status of the SNURF-SNRPN gene was determined by bisulphite treatment of genomic DNA and methylation specific PCR. ${ }^{12}$ For segregation analysis of microsatellite loci along chromosome 15, fluorescence tagged PCR products were analysed on an ABI Prism 3100 Genetic Analyzer, using GeneScan and Genotyper software (ABI, Foster City, CA, USA). In accordance with established diagnostic criteria, patients carrying an unmethylated maternal SNURF-SNRPN allele were classified as having an ID. In all patients with an ID, a familial imprinting centre (IC) deletion was excluded by quantitative real time PCR analysis of the critical IC elements (Buiting and Horsthemke, unpublished).

\section{RESULTS}

Of 270 members, $82(30 \%)$ replied. One child was adopted; two other parents refused to give detailed information. Thus, 79 valid questionnaires were returned. Sixteen children (20\%) were born to subfertile couples (defined as having had a TTP $>2$ years and/or infertility treatment). This is a higher rate than that expected in the general population $(\sim 10-15 \%)$ and indicates a reporting bias. However, this bias

Abbreviations: AS, Angelman syndrome; ICSI, intracytoplasmic sperm injection; IC, imprinting centre; ID, imprinting defect; TTP, time to pregnancy 


\begin{tabular}{|c|c|c|c|c|}
\hline Family & $\begin{array}{l}\text { TTP } \\
>2 \text { years }\end{array}$ & $\begin{array}{l}\text { HT } \\
\text { only }\end{array}$ & ICSI & $\begin{array}{l}\text { Genetic } \\
\text { lesion }\end{array}$ \\
\hline 1 & + & + & & Deletion \\
\hline 2 & + & + & & \\
\hline 3 & + & & + & Deletion \\
\hline 4 & + & & + & \\
\hline 5 & + & & & Deletion \\
\hline 6 & + & & & Other \\
\hline 7 & + & & & Deletion \\
\hline 8 & + & & & \\
\hline 9 & + & & & Deletion \\
\hline 10 & + & & & Deletion \\
\hline 11 & + & & & ID \\
\hline 12 & + & & & Deletion \\
\hline 13 & & + & & Other \\
\hline 14 & & + & & Deletion \\
\hline 15 & & + & & Deletion \\
\hline 16 & & & + & Deletion \\
\hline
\end{tabular}

does not affect our results, because we have compared the percentage of IDs in this group with the percentage of IDs in all patients with Angelman syndrome.

Four of the sixteen children $(25 \%)$ were found to have a sporadic ID (table 1). Assuming that an ID accounts for $4 \%$ of AS patients (see above), the relative risk (RR) was significantly increased in this group of patients (table 2). The RR was increased by the same factor in the untreated subgroup of couples with TTP $>2$ years $(n=8)$ and in the subgroup of couples who underwent ICSI or hormone treatment $(n=8)$, although the increase did not reach statistical significance. We noted that there was one ID child in each of the ICSI $(n=3)$ and the hormone treatment only $(\mathrm{n}=5)$ groups. RR was highest in couples with TTP $>2$ years who had also undergone infertility treatment $(n=4)$. This increase was statistically significant.

\section{DISCUSSION}

In the present study we found that subfertile couples have an increased risk of conceiving a child with an imprinting defect causing AS. The increased RR in untreated couples with TTP $>2$ years suggests that imprinting defects and subfertility may have a common cause. This observation is supported by data showing that an increased TTP alone is a significant risk factor for the development of pre-eclampsia or intrauterine growth retardation. ${ }^{13-15}$ This risk of pregnancy complications associated with an increased TTP is similiar to that observed in pregnancies conceived after $\mathrm{ICSI}^{4}$ or assisted reproduction in general. ${ }^{16}$

Interestingly, early embryonic development and intrauterine growth are critically dependent on the proper function of imprinted genes. ${ }^{17}$ Based on these findings, we propose that there is some genetic predisposition, possibly of a heterogeneous nature, to epigenetic instability of gametes or early embryonic cells. Depending on the number and type of affected loci in these cells, epigenetic instability can lead to early developmental failure, which may manifest as subfertility, intrauterine growth retardation, or congenital anomalies.

As the RR was twice as high in couples with TTP $>2$ years who had undergone hormonal stimulation or ICSI, infertility treatment may further increase the risk of conceiving a child with ID. One possible explanation is that these couples suffered from a more severe form of subfertility that necessitated infertility treatment. Alternatively, hormonal stimulation, which is also used for ICSI, may lead to the maturation of "poor quality" oocytes that would not have
Table 2 Relative risk (RR) and 95\% confidence interval (CI) to have a child with an imprinting defect (ID)

\begin{tabular}{|c|c|c|c|c|}
\hline \multirow[b]{2}{*}{ Details } & \multirow[b]{2}{*}{$\mathbf{n}$} & \multicolumn{3}{|c|}{ Children with an ID } \\
\hline & & Obs. & $\begin{array}{l}\text { Exp. } \\
(4 \%)\end{array}$ & $\operatorname{RR}(95 \% \mathrm{Cl})$ \\
\hline HT only & 5 & 1 & 0.20 & $5.00(0.07$ to 27.82$)$ \\
\hline ICSI & 3 & 1 & 0.12 & $8.33(0.11$ to 46.37$)$ \\
\hline HT or ICSI & 8 & 2 & 0.32 & 6.25 (0.70 to 22.57$)$ \\
\hline TाP $>2$ years, no therapy & 8 & 2 & 0.32 & 6.25 (0.70 to 22.57$)$ \\
\hline TTP $>2$ years or therapy & 16 & 4 & 0.64 & 6.25 (1.68 to 16.00$)$ \\
\hline TाP $>2$ years and therapy & 4 & 2 & 0.16 & $12.50(1.40$ to 45.13$)$ \\
\hline
\end{tabular}

been ovulated without treatment, or that a too rapid maturation provoked by the hormonal stimulation procedure disturbs the process of DNA methylation in the oocyte. A lower oocyte quality following ovarian stimulation procedures has already been suggested from studies in the mouse. ${ }^{18}$

As our cohort of patients does not contain children conceived by conventional in vitro fertilisation without ICSI or intrauterine insemination, we do not know whether gamete and embryo culture or embryo manipulation increases the risk for an ID, as has been shown in animal studies. ${ }^{19}$

In summary, we have demonstrated for the first time that the prevalence of imprinting defects in patients with AS born to subfertile couples is significantly increased. Our data suggest that imprinting defects and subfertility may have a common cause, and that superovulation, rather than ICSI, may further increase the risk of conceiving a child with an imprinting defect. However, the absolute risk remains small.

\section{ACKNOWLEDGEMENTS}

Part of this study was supported by the Deutsche Forschungsgemeinschaft and an unconditional grant from Serono $\mathrm{GmbH}$, Germany.

\section{Authors' affiliations}

\section{Ludwig, Endokrinologikum Hamburg, Germany}

A Katalinic, Institut für Krebsepidemiologie, Medizinische Universität Lübeck, Germany

S Groß, B Horsthemke, Institut für Humangenetik, Universitätsklinikum Essen, Germany

A Sutcliffe, Department of Paediatrics, University College London, UK R Varon, Institut für Humangenetik, Charité, Humboldt Universität Berlin, Germany

\section{Competing interests: none declared}

M Ludwig and A Sutcliffe designed the study. M Ludwig recruited the patients. A Katalinic gave advice on the study design, performed the statistical analysis. S Groß and R Varon performed the DNA studies. B Horsthemke collected the samples and evaluated the molecular data. $M$ Ludwig and B Horsthemke interpreted the results and wrote the manuscript.

\section{REFERENCES}

1 Palermo G, Joris H, Devroey P, Van Steirteghem AC. Pregnancies after intracytoplasmic injection of single spermatozoon into an oocyte. Lancet 1992;340:17-18.

2 Bonduelle M, Liebaers I, Deketelaere V, Derde MP, Camus M, Devroey P, Van Steirteghem A. Neonatal data on a cohort of 2889 infants born after ICSI (1991-1999) and of 2995 infants born after IVF (1983-1999). Hum Reprod 2002; 17:671-94.

3 Hansen M, Kurinczuk JJ, Bower C, Webb S. The risk of major birth defects after intracytoplasmic sperm injection and in vitro fertilization. N Engl J Med 2002;346:725-30.

4 Katalinic A, Rösch C, Ludwig M. Pregnancy course and outcome after intracytoplasmic sperm injection (ICSI) - a controlled, prospective cohort study. Fertil Steril 2004;81:1604-16. 
5 Schieve LA, Meikle SF, Ferre C, Peterson HB, Jeng G, Wilcox LS. Low and very low birth weight in infants conceived with use of assisted reproductive technology. N Engl J Med 2002;346:731-7.

6 Cox GF, Burger J, Lip V, Mau UA, Sperling K, Wu BL. Intracytoplasmic sperm injection may increase the risk of imprinting defects. Am J Hum Genet 2002;71:162-64.

7 Orstavik KH, Eiklid K, van der Hagen CB, Spetalen S, Kierulf K, Skjeldal O, Buiting K. Another case of imprinting defect in a girl with Angelman syndrome who was conceived by intracytoplasmic semen injection. Am J Hum Genet 2003:72:218-19.

8 Maher ER, Brueton LA, Bowdin SC, Luharia A, Cooper W, Cole TR, Macdonald F, Sampson JR, Barratt CL, Reik W, Hawkins MM. BeckwithWiedemann syndrome and assisted reproduction technology (ART). J Med Genet 2003:40:62-4.

9 DeBaun MR, Niemitz EL, Feinberg AP. Association of in vitro fertilization with Beckwith-Wiedemann syndrome and epigenetic alterations of LIT1 and H19. Am J Hum Genet 2003;72:156-60.

10 Gicquel C, Gaston V, Mandelbaum J, Siffroi JP, Flahault A, Le Bouc Y. In vitro fertilization may increase the risk of Beckwith-Wiedemann syndrome related to the abnormal imprinting of the KCNIOT gene. Am J Hum Genet 2003;72:1338-41.

11 Lossie AC, Whitney MM, Amidon D, Dong HJ, Chen P, Theriaque D, Hutson A, Nicholls RD, Zori RT, Williams CA, Driscoll DJ. Distinct phenotypes distinguish the molecular classes of Angelman syndrome. J Med Genet 2001;38:834-45

12 Zeschnigk M, Lich C, Buiting K, Doerfler W, Horsthemke B. A single-tube PCR test for the diagnosis of Angelman and Prader-Willi syndrome based on allelic methylation differences at the SNRPN locus. Eur J Hum Genet 1997:5:94-8.

13 Basso O, Weinberg CR, Baird DD, Wilcox AJ, Olsen J. Subfecundity as a correlate of preeclampsia: a study within the Danish National Birth Cohort. Am J Epidemiol 2003;157:195-202.

14 Henriksen TB, Baird DD, Olsen J, Hedegaard M, Secher NJ, Wilcox AJ. Time to pregnancy and preterm delivery. Obstet Gynecol 1997;89:594-9.

15 Pandian Z, Bhattacharya S, Templeton A. Review of unexplained infertility and obstetric outcome: a 10 year review. Hum Reprod $2001 ; 16: 2593-7$

16 Helmerhorst FM, Perquin DA, Donker D, Keirse MJ. Perinatal outcome of singletons and twins after assisted conception: a systematic review of controlled studies. BMJ 2004;328:261.

17 Miozzo M, Simoni G. The role of imprinted genes in fetal growth. Biol Neonate 2002:81:217-28.

18 Ertzeid G, Storeng R. The impact of ovarian stimulation on implantation and fetal development in mice. Hum Reprod 2001;16:221-5.

19 Niemitz EL, Feinberg AP. Epigenetics and assisted reproductive technology: a call for investigation. Am J Hum Genet 2004;74:599-609.

\section{$\mathrm{ECHO}$}

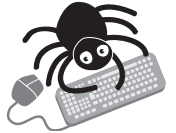

Please visit the Journal of Medical Genetics website [www. imedgenet. com] for a link to the full text of this article.
Further evidence of genetic heterogeneity in familial exudative vitreoretinopathy; exclusion of EVR1, EVR3, and EVR4 in a large autosomal dominant pedigree C Toomes, L M Downey, H M Bottomley, H A Mintz-Hittner, C F Inglehearn

Background/aims: Familial exudative vitreoretinopathy (FEVR) is an inherited blinding condition characterised by abnormal development of the retinal vasculature. The aim of this study was to perform linkage analysis in a large family affected with FEVR to determine whether the mutation involved was in one of the three known autosomal dominant FEVR loci or in another as yet unidentified gene.

Methods: Genomic DNA samples from family members were polymerase chain reaction (PCR) amplified with fluorescently tagged microsatellite markers spanning the EVRI/EVR4 locus (11q13-14) and the EVR3 locus (11p12-13). The resulting PCR products were resolved using an automated DNA sequencer and the alleles sized. These data were used to construct haplotypes across each locus and linkage analysis was performed to prove or exclude linkage.

Results: The clinical evaluation in this family suggested features typical of FEVR, with deficient peripheral retinal vascularisation being the common phenotype in all affected individuals. However, linkage analysis proved that this family has a form of FEVR genetically distinct from the EVRI, EVR3 and EVR4 loci.

Conclusion: The exclusion of linkage in this family to any of the known FEVR loci proves the existence of a fourth locus for autosomal dominant FEVR and shows that this rare disorder is far more heterogeneous than previously thought.

A British Journal of Ophthalmology 2005;89:194-197. 